\title{
Bilirubin and Heme as Growth Inhibitors of Chicken Embryos in Ovo
}

\author{
RENA VASSILOPOULOU-SELLIN, PAULETTE FOSTER, AND CAROLINE O. OYEDEJI
}

Section of Endocrinology, Department of Medical Specialties, The University of Texas M. D. Anderson Cancer

Center, Houston, Texas 77030

\begin{abstract}
The increased morbidity during pregnancies complicated by hematologic or liver disease has generally been attributed to the metabolic abnormalities of the illness itself. Because tetrapyrrole concentrations are elevated in these conditions, we introduced bilirubin or heme (prepared as $10 \mathrm{mM}$ solutions) into the air sac of fertilized chicken eggs to study their effect on the growth of normal chicken embryos. In 9-d eggs, the injection of $0.06 \mathrm{~mL}$ heme resulted in significant embryo growth inhibition as indicated by overall wt $(91 \pm 3 \%$ versus control), tibia length $(84 \pm 2 \%)$, tibia wt $(81 \pm 3 \%)$, femur length $(88 \pm 1 \%)$, and femur wt $(78 \pm 3 \%)$; doses greater than $0.10 \mathrm{~mL}$ resulted in substantial fetal losses. The injection of 0.06 $\mathrm{mL}$ bilirubin into the same-age eggs also resulted in less than normal tibia length $(87 \pm 2 \%$ versus control), tibia wt $(75 \pm 4 \%)$, femur length $(91 \pm 2 \%)$, and femur wt (81 \pm $3 \%)$; larger doses resulted in more pronounced growth inhibition, but fetal losses were less common than with heme. Older chick embryos (12-d) appeared more resistant to the effects of bilirubin: $0.15 \mathrm{~mL}$ bilirubin inhibited only tibia and femur wt; larger doses were required to significantly suppress the other growth parameters. The sameage chicken embryos, however, remained exquisitely sensitive to heme; $0.05 \mathrm{~mL}$ resulted in less than normal whole embryo wt $(88 \pm 2 \%$ versus control), tibia length $(80 \pm$ $1 \%)$, tibia wt $(76 \pm 1 \%)$, femur length $(78 \pm 1 \%)$, and femur wt $(77 \pm 1 \%)$. Substantial fetal loss occurred with heme doses above $0.10 \mathrm{~mL}$ as well as among the less mature chicks. Significant inhibition of the growth of long bones (tibia and femur) also occurred when we added 0.05 $\mathrm{mM}$ bilirubin or $0.025 \mathrm{mM} \mathrm{Hb}$ to bones maintained in organ culture in vitro for $5 \mathrm{~d}$. We conclude that several heme compounds and bilirubin inhibit the growth and survival of normal chick embryos in ovo and in vitro. We suggest that prenatal exposure to high levels of these compounds may have a previously underestimated negative influence on fetal development (Pediatr Res 27: 617-621, 1990)
\end{abstract}

In pregnancies complicated by maternal hematologic or liver diseases, the risk of adverse fetal outcome is higher than normal. How these maternal illnesses harm the fetus remains poorly understood (1-3). Although maternal hematologic or liver diseases are systemic disorders with multiple metabolic abnormalities that could affect fetal outcome, one feature they share is sustained elevation of circulating tetrapyrroles (heme compounds and/or bilirubin), which may affect fetal metabolism directly.

Received October 2, 1989; accepted February 14, 1990

Correspondence and reprint requests: Rena Vassilopoulou-Sellin, M.D., Section of Endocrinology, Box 15, The University of Texas M. D. Anderson Cancer Center, 1515 Holcombe Boulevard, Houston, TX 77030.

Supported by NIH Grant AR 37326
That exposure to heme compounds or bilirubin may exert a direct negative influence on fetal growth and development has not received attention, but our recent studies prompt us to examine this possibility carefully. We have demonstrated that several tetrapyrroles can profoundly inhibit the growth of embryonic chicken cartilage in organ culture in vitro (4-7), the growth of normal, growing rats in vivo (8), and the proliferation of chondrocytes in cell culture (9). Whereas the potential range of tetrapyrrole-induced inhibition in tissues other than cartilage has not yet been specifically demonstrated, a broader antianabolic effect is suggested by the observed dose-dependent growth retardation of intact rats overloaded with heme in vivo (8).

We designed this study to assess whether bilirubin and heme can influence the growth and development of normal, growing chick embryos in ovo and to define the potential of this experimental model for further studies of tetrapyrrole action.

\section{MATERIALS AND METHODS}

Materials. Waymouth's tissue culture medium was from GIBCO Laboratories (Grand Island, NY), FCS was from Hazleton Biologicals (Lenexa, KS). Bovine hemin (heme), crystalline bilirubin, $\mathrm{Hb}$, and all other chemicals were from Sigma Chemical (St. Louis, MO). Fertilized chicken eggs were from Richglo (El Campo, TX).

Unconjugated bilirubin was dissolved at $\mathrm{pH} 10$ with $2 \mathrm{~N}$ $\mathrm{NaOH}$; albumin was then stirred in, and $\mathrm{pH}$ adjusted back to 7.7 to prepare a $10 \mathrm{mM}$ stock solution containing $1 \mathrm{mg} / \mathrm{mL}$ albumin (7). Fresh solutions were made twice a wk and stored in opaque containers at $4^{\circ} \mathrm{C}$; our previous studies demonstrated that the addition of excess albumin does not modify the bioactivity of bilirubin (7). Heme (or $\mathrm{Hb}$ ) powder was brought into solution at $\mathrm{pH} 11$ with $2 \mathrm{~N} \mathrm{NaOH}$, pH was titrated back to 7.7, and a $10 \mathrm{mM}$ stock solution was prepared, which was also stored at $4^{\circ} \mathrm{C}(6)$. All treatment solutions were filtered through 0.022 nm Millipore filters (Millipore, Bedford, MA) before injection. Heme concentrations were confirmed spectrophotometrically and bilirubin concentrations by the clinical chemistry laboratory in representative samples.

Administration of heme/bilirubin in ovo. The injection methods were modified from previous studies (10-15). Fertilized eggs were maintained at $37^{\circ} \mathrm{C}$ during the experimental period. Before injection, the blunt end was cleaned with alcohol and allowed to dry. The eggshell was then punctured through the air sac with a 23-gauge needle attached to a 1-mL syringe, and the appropriate treatment solution was introduced into the air sac. The puncture hole was sealed with wax and the egg returned to the incubator. In preliminary experiments, we evaluated the effect of injecting $0.05-0.60 \mathrm{~mL}$ buffer and found that the measured growth parameters were no different from those for uninjected eggs. Thus, the lower end of this volume range was chosen; in all experiments, a buffer solution was injected into the eggs designated as controls.

At the end of the incubation period, the shells were cracked, and the embryos inspected for a spontaneous heartbeat; only live 
embryos were used for the accumulation of growth parameter data. The embryos were cleansed of other egg contents and weighed; they were then dissected, and tissues were removed for measurement. The pelvis and the hind legs were separated and cleansed of adjacent soft tissues; the tibia and femur lengths were measured with calipers, and the pelvic rudiment, tibia, and femur were weighed both wet and after stepwise dehydration in ethanol and ether. The correlation between wet and dry wt was excellent (dry:wet ratio, $23 \pm 0.4 \%$ for 345 bones), and the data are generally given as wet wt.

In the time-course experiments, 9-d eggs were injected with $0.1 \mathrm{~mL}$ heme or buffer, and growth parameters compared after 2,4 , or $7 \mathrm{~d}$. The impact of a single dose of heme was most apparent between 2 and $4 \mathrm{~d}$. In dose-response studies, therefore, a 3 -d interval was chosen.

The doses of heme or bilirubin were only semiquantitative. Based on the average egg wt of $50-55 \mathrm{~g}$, the volume was approximately $50 \mathrm{~mL}$; we used a range from $0.05 \mathrm{~mL}$ (i.e. $0.3 \mathrm{mg} / \mathrm{egg}$ or approximately $0.01 \mathrm{mM}$ ) to $0.60 \mathrm{~mL}$ (i.e. $3.6 \mathrm{mg} / \mathrm{egg}$ or approximately $0.6 \mathrm{mM}$ ), concentrating on a $0.05-0.15 \mathrm{~mL}$ injected volume in most experiments. Our previous in vitro studies demonstrated significant growth inhibition with $0.05-0.10 \mathrm{mM}$ heme or bilirubin $(6,7)$; furthermore, these concentrations are consistent with the circulating levels of bilirubin (or heme) likely to prevail in clinical conditions (from $0.05 \mathrm{mM}$ or $3 \mathrm{mg} / \mathrm{dL}$ to $0.15 \mathrm{mM}$ or $9 \mathrm{mg} / \mathrm{dL}$ ).

Prolonged organ cultures. Prolonged organ cultures were modified from previous studies (4-7). Briefly, pelvic rudiments, tibiae, and femurs were removed from 11-d-old chick embryos; they were cleansed of adjacent tissues and incubated in Waymouth's MB 752/1 tissue culture medium with $10 \%$ FCS and test substances for $5 \mathrm{~d}$ (with fresh media at $2 \mathrm{~d}$ ). Femur and tibia length was measured with calipers at 0,2 , and $5 \mathrm{~d}$, and dry wt at $5 \mathrm{~d}$. Pelvic rudiment wet wt was obtained at 0,2 , and $5 \mathrm{~d}$ for comparison with our previous studies (4-7). Tissue measurements at 2 and $5 \mathrm{~d}$ were expressed as percentages of initial measurements.

Statistical analysis. Differences between means were evaluated by $t$ test.

\section{RESULTS}

Heme or bilirubin introduction into fertilized chicken eggs. At the end of the incubation period, the chorio-allantoic membranes were still stained with the black pigment of heme or the yellowishgreen pigment of bilirubin. The livers of the treated chicks were darker than controls, but there was no significant difference in their wt. Although we encountered two deformed chicks in bilirubin-treated eggs, we consider this a probable coincidence because of the chick age at injection. In the older chicks (injected at $12 \mathrm{~d}$ ), the pelvic rudiment normally has evidence of calcification and becomes invaded with blood vessels; both of these developmental changes were absent in the treated chicks. In addition, the treated chicks had poorly developed beaks and nails, a relatively immature eye configuration, and scantier feather cover.

Finally, the larger doses of bilirubin and especially heme were very toxic and resulted in substantial fetal losses (Table 1). Although the injection of buffer and of low-dose heme or bilirubin were well tolerated, resulting in minimal $(5-7 \%)$ fetal loss (equivalent to the incidence in untreated eggs), fetal losses were greater than $40 \%$ at higher doses. Thus, in ovo exposure to bilirubin or heme can be lethal to the growing chick embryo.

Time course study of effect of one injection of heme in ovo. In 9 -d eggs, significant growth retardation was evident $2 \mathrm{~d}$ after the administration of $0.10 \mathrm{~mL}$ heme (Table 2). This was reflected in below normal overall embryo wt, tibia and femur wt and length, and pelvic rudiment wt. Some growth delay persisted after $4 \mathrm{~d}$ but apparent catch-up growth restored the size of the treated chicks by $7 \mathrm{~d}$. Thus, the growth inhibition induced by a modest
Table 1. Fetal losses after heme/bilirubin administration

\begin{tabular}{lcc}
\hline \multirow{2}{*}{ Treatment group } & \multicolumn{2}{c}{ Chick embryo age* } \\
\cline { 2 - 3 } & $9 \mathrm{~d}$ & $12 \mathrm{~d}$ \\
\hline Control† & $1 / 19 \ddagger$ & $2 / 27$ \\
Heme $0.05-0.10 \mathrm{~mL} \S$ & $1 / 17$ & $1 / 18$ \\
Heme $0.11-0.15 \mathrm{~mL}$ & $17 / 36$ & $8 / 21$ \\
Heme $0.20-0.30 \mathrm{~mL}$ & $5 / 6$ & $20 / 29$ \\
Bili $0.05-0.10 \mathrm{~mL}$ & $2 / 17$ & $\mathrm{ND}$ \\
Bili $0.11-0.15 \mathrm{~mL}$ & $9 / 36$ & $1 / 11$ \\
Bili $0.10-0.60 \mathrm{~mL}$ & $13 / 48$ & $2 / 11$ \\
\hline
\end{tabular}

* Embryo age at time of injection.

$\uparrow$ Buffer injected.

$\ddagger$ Number of dead embryos/total number of embryos examined.

$\S$ Test solution was $10 \mathrm{mM}$; injected vol in $\mathrm{mL}$.

|| Bili, bilirubin; ND, not determined.

dose of heme is evident within $2 \mathrm{~d}$ but no longer affects chick growth by the 7 th $\mathrm{d}$. Furthermore, low-dose heme administration causes readily reversible inhibition of chick growth, whereas high doses of heme can be lethal to the growing embryos.

Dose-response study of effect of heme and bilirubin on growth of 9-d chick embryos. Nine-d-old chicks (starting wt $2.86 \pm 0.07$ g) were injected with increasing concentrations of heme or bilirubin, and growth parameters were measured after $3 \mathrm{~d}$ (Table 3 ). Because of substantial fetal losses with higher doses, only the effect of the lower concentrations was analyzed. A significant decrease in several growth parameters was found in all treated groups. The impact on long bone growth (both length and wt) was the most consistent; tibia or femur size was $10-25 \%$ less than normal at all concentrations of heme and bilirubin. Overall embryo and pelvic rudiment sizes were, generally, smaller at the higher doses. The tissues of the treated chicks were more friable than controls but morphologically normal. Thus, the exposure of immature chick embryos to modest doses of heme or bilirubin results in significant growth retardation in ovo.

Dose-response study of effects of heme and bilirubin on growth of 12-d chick embryos. A separate group of more mature, 12-d, chick embryos (starting wt $7.32 \pm 0.17 \mathrm{~g}$ ) was injected with increasing doses of heme or bilirubin, and growth parameters were measured after $3 \mathrm{~d}$ (Table 4). To assess potential age-related changes in sensitivity to ambient tetrapyrroles, we adjusted the injected doses for chick size. (Thus, $0.15 \mathrm{~mL}$ for this group is approximately equivalent to $0.06 \mathrm{~mL}$ for the 9-d group, and 0.30 $\mathrm{mL}$ is equivalent to $0.13 \mathrm{~mL}$.) These more mature chicks appear to be relatively resistant to the inhibitory effects of bilirubin, since the $0.15 \mathrm{~mL}$ dose caused only partial and modest decrease in tibia and femur wt; more pronounced inhibition was found with the higher $0.30 \mathrm{~mL}$ dose. Fetal losses were also less common. The administration of heme, however, resulted in profound growth inhibition even at low concentrations; embryos, tibiae, and femurs were significantly smaller than normal after $0.05 \mathrm{~mL}$ heme injections with striking inhibition of all growth parameters and a substantial fetal loss rate at the larger $0.30 \mathrm{~mL}$ dose. The heme-induced inhibition in this group appeared more severe than the effect of equivalent doses in the 9-d chicks.

Effects of bilirubin and $\mathrm{Hb}$ on growth of embryonic chick skeletal tissues in vitro. We also assessed the effect of bilirubin or $\mathrm{Hb}$ on the growth of long bones directly by adding these compounds to tibiae and femurs maintained in organ culture for $5 \mathrm{~d}$ (Table 5). In these experiments, we substituted $\mathrm{Hb}$ for heme, as this related heme compound can also become elevated in hematologic diseases. Our previous studies demonstrated that $\mathrm{Hb}$ inhibits embryonic chick pelvic rudiment growth and that the inhibition is attributable to the heme portion of the $\mathrm{Hb}$ molecule (5). Pelvic rudiment measurements were included for comparison with our previous studies; the observed inhibition was consistent with those results (4-7). Both $0.05 \mathrm{mM}$ bilirubin and $0.25 \mathrm{mM} \mathrm{Hb}$ produced modest but significant $8-12 \%$ de- 
Table 2. Effect of one heme injection on growth of chick embryos in ovo-time course study*

\begin{tabular}{|c|c|c|c|c|c|}
\hline Tissue & Treatment & d $0(9-d)$ & $\mathrm{d} 2(11-\mathrm{d})$ & d 4 (13-d) & $\mathrm{d} 7(16-\mathrm{d})$ \\
\hline Whole embryo $(\mathrm{g})$ & $\begin{array}{l}\text { Control } \\
\text { Heme }\end{array}$ & $2.68 \pm 0.07$ & $\begin{array}{l}5.93 \pm 0.06 \\
5.31 \pm 0.14 \dagger\end{array}$ & $\begin{array}{l}9.38 \pm 0.17 \\
8.34 \pm 0.72\end{array}$ & $\begin{array}{l}16.95 \pm 0.53 \\
14.15 \pm 1.56\end{array}$ \\
\hline Pelvic rudiments (mg) & $\begin{array}{l}\text { Control } \\
\text { Heme }\end{array}$ & $2.07 \pm 0.20$ & $\begin{array}{r}10.31 \pm 0.47 \\
7.75 \pm 0.38\end{array}$ & $\begin{array}{l}13.79 \pm 0.86 \\
14.23 \pm 1.15\end{array}$ & $\begin{array}{l}47.44 \pm 1.92 \\
45.56 \pm 3.36\end{array}$ \\
\hline Tibia length (mm) & $\begin{array}{l}\text { Control } \\
\text { Heme }\end{array}$ & $9.00 \pm 0.27$ & $\begin{array}{l}11.25 \pm 0.31 \\
10.80 \pm 0.29\end{array}$ & $\begin{array}{l}16.37 \pm 0.18 \\
13.90 \pm 0.10 \dagger\end{array}$ & $\begin{array}{l}21.12 \pm 0.44 \\
19.13 \pm 1.19\end{array}$ \\
\hline Tibia wt (mg) & $\begin{array}{l}\text { Control } \\
\text { Heme }\end{array}$ & $2.99 \pm 0.18$ & $\begin{aligned} 11.65 & \pm 0.74 \\
8.38 & \pm 0.45 \dagger\end{aligned}$ & $\begin{array}{l}22.41 \pm 0.59 \\
17.74 \pm 1.17 \dagger\end{array}$ & $\begin{array}{l}62.06 \pm 2.46 \\
62.39 \pm 4.13\end{array}$ \\
\hline Femur length (mm) & $\begin{array}{l}\text { Control } \\
\text { Heme }\end{array}$ & $7.12 \pm 0.35$ & $\begin{array}{r}9.25 \pm 0.25 \\
8.0 \pm 0.26 \dagger\end{array}$ & $\begin{array}{r}11.12 \pm 0.23 \\
9.60 \pm 0.22\end{array}$ & $\begin{array}{l}16.12 \pm 0.40 \\
14.50 \pm 0.50\end{array}$ \\
\hline Femur wt (mg) & $\begin{array}{l}\text { Control } \\
\text { Heme }\end{array}$ & $2.12 \pm 0.10$ & $\begin{aligned} 10.00 & \pm 0.45 \\
6.09 & \pm 0.32 \dagger\end{aligned}$ & $\begin{array}{l}14.71 \pm 0.29 \\
12.79 \pm 0.95\end{array}$ & $\begin{array}{l}43.49 \pm 2.00 \\
36.24 \pm 3.20\end{array}$ \\
\hline
\end{tabular}

* Fertilized eggs (9-d) were injected with $0.1 \mathrm{~mL}$ of heme solution or buffer. Values are mean $\pm \mathrm{SEM}, n=4-5$ eggs each time point.

$\dagger p<0.05$ vs control.

Table 3. Effect of heme/bilirubin on growth of 9-d-old chick embryos*

\begin{tabular}{|c|c|c|c|c|}
\hline Tissue & Control $\dagger$ & H $0.06(\%)+$ & $\mathrm{H} 0.08(\%) \ddagger$ & H $0.11(\%) \ddagger$ \\
\hline Embryo wt & $8.35 \pm 0.4(\mathrm{~g})$ & $91 \pm 4$ & $91 \pm 3$ & $97 \pm 5$ \\
\hline Tibia length & $15.40 \pm 0.3(\mathrm{~mm})$ & $84 \pm 2 \S$ & $86 \pm 1 \S$ & $85 \pm 1 \S$ \\
\hline Tibia wt & $22.45 \pm 1.2(\mathrm{mg})$ & $81 \pm 3 \S$ & $86 \pm 3 \S$ & $84 \pm 3 \S$ \\
\hline Femur length & $10.71 \pm 0.2(\mathrm{~mm})$ & $88 \pm 1 \S$ & $89 \pm 1 \S$ & $90 \pm 2 \S$ \\
\hline Femur wt & $15.49 \pm 0.8(\mathrm{mg})$ & $78 \pm 3 \S$ & $88 \pm 3 \S$ & $84 \pm 4 \S$ \\
\hline Pelvis wt & $17.21 \pm 0.9(\mathrm{mg})$ & $103 \pm 3$ & $88 \pm 4 \S$ & $88 \pm 4 \S$ \\
\hline \multirow[t]{2}{*}{ Fetal loss } & $1 / 19$ & $0 / 6$ & $1 / 11$ & $5 / 11$ \\
\hline & В $0.06(\%) \ddagger$ & В $0.08(\%) \ddagger$ & B $0.11(\%) \neq$ & В $0.30(\%) \ddagger$ \\
\hline Embryo wt & $91 \pm 7$ & $91 \pm 5$ & $80 \pm 4 \S$ & $92 \pm 3 \S$ \\
\hline Tibia length & $87 \pm 2 \S$ & $86 \pm 1 \S$ & $85 \pm 3 \S$ & $93 \pm 1 \S$ \\
\hline Tibia wt & $75 \pm 4 \S$ & $71 \pm 3 \S$ & $70 \pm 3 \S$ & $80 \pm 3 \S$ \\
\hline Femur length & $91 \pm 2 \S$ & $91 \pm 2 \S$ & $86 \pm 1 \S$ & $94 \pm 1 \S$ \\
\hline Femur wt & $81 \pm 3 \S$ & $83 \pm 4 \S$ & $76 \pm 7 \S$ & $82 \pm 2 \S$ \\
\hline Pelvis wt & $74 \pm 3 \S$ & $76 \pm 6 \S$ & $74 \pm 4 \S$ & $84 \pm 2 \S$ \\
\hline Fetal loss & $2 / 11$ & $0 / 6$ & $5 / 12$ & $3 / 26$ \\
\hline
\end{tabular}

* Heme $(\mathrm{H})$ and bilirubin $(\mathrm{B})$ dose expressed as injected vol in $\mathrm{mL}$, mean $\pm \mathrm{SEM}$.

$\dagger$ Growth parameters expressed as direct measurement.

+ Growth parameters expressed as percentages of the appropriate controls within each assay.

$\S p<0.05$ vs control.

creases in tibia and femur length after 2 and $5 \mathrm{~d}$ as well as in bone wt at the conclusion of the organ culture period. Thus, these compounds modify the growth potential of skeletal tissues both systemically in ovo and directly in vitro.

\section{DISCUSSION}

Our study demonstrates that exposure of normal, growing chicken embryos to modest concentrations of bilirubin or heme causes severe growth retardation and increased fetal loss. Thus, ambient tetrapyrroles may have a previously underestimated impact on growth and development.

Several hereditary hematologic (16) and liver (17-20) diseases are associated with growth failure and specific skeletal anomalies. These complications are generally attributed to nonspecific factors relating to systemic metabolic derangements but are poorly understood. In addition, maternal hematologic or liver dysfunction during pregnancy is associated with increased fetal deaths $(1-3)$; this is attributed to the maternal metabolic dysregulation, but the pathophysiology remains ill-defined. Our findings support the concept that abnormally circulating heme compounds and their metabolites, which prevail in hematologic and liver disease, can be directly responsible for at least some of the fetal abnormalities.

How tetrapyrroles inhibit growth is not clear, but our in vitro studies of cartilage growth models demonstrate that these compounds interfere with overall tissue growth as well as radiolabeled isotope incorporation into RNA/protein/proteoglycans (4-9). Ample evidence suggests other metabolic activities of tetrapyrrole compounds. Heme can inhibit the growth of erythropoetic (21, 22 ) and ovarian cell lines (23) and is a naturally occurring ligand for peripheral benzodiazepine receptors $(24,25)$. Bilirubin can abolish respiratory control, uncouple oxidative phosphorylation, and induce mitochondrial swelling in liver, heart, brain tissues (26), and cultured cells (27); it has also been shown to lower mitochondrial ATP and electrolyte content in renal slices (28) and to inhibit superoxide production by polymorphonuclear cells (29). Hematoporphyrins are potent cytocidal agents in tumor phototherapy $(30,31)$ but can also inhibit cartilage metabolism (32) and cell proliferation $(33,34)$ in the absence of light. Finally, bile pigments are vital to lower organisms, being responsible for the spectrum of photosynthetic energy transfer reactions (17). Thus, these compounds possess the intrinsic ability to interact with a wide variety of tissues, in which they exert a broad range of antianabolic effects. 
Table 4. Effect of heme/bilirubin on growth of 12-d-old chick embryos*

\begin{tabular}{|c|c|c|c|}
\hline Tissue & Control $\dagger$ & B $0.15 \div$ & В $0.30 \ddagger$ \\
\hline Embryo wt & $14.9 \pm 0.5(\mathrm{~g})$ & $90 \pm 5 \%$ & $80 \pm 3 \% \S$ \\
\hline Tibia length & $20.6 \pm 0.4(\mathrm{~mm})$ & $100 \pm 3 \%$ & $90 \pm 3 \% \S$ \\
\hline Tibia wt & $58.9 \pm 2.3(\mathrm{mg})$ & $90 \pm 4 \% \S$ & $71 \pm 3 \% \S$ \\
\hline Femur length & $14.4 \pm 0.3(\mathrm{~mm})$ & $97 \pm 3 \%$ & $95 \pm 3 \%$ \\
\hline Femur wt & $39.7 \pm 1.7(\mathrm{mg})$ & $82 \pm 3 \% \S$ & $68 \pm 4 \% \S$ \\
\hline Pelvis wt & $39.3 \pm 1.7(\mathrm{mg})$ & $109 \pm 4 \%$ & $80 \pm 4 \% \S$ \\
\hline \multirow[t]{2}{*}{ Fetal loss } & $2 / 27$ & $1 / 11$ & $2 / 11$ \\
\hline & $\mathrm{H} 0.05 \ddagger$ & H 0.075 末 & $\mathrm{H} 0.30$ \\
\hline Embryo wt & $88 \pm 2 \% \S$ & $83 \pm 3 \% \S$ & $64 \pm 7 \% \S$ \\
\hline Tibia length & $80 \pm 1 \% \S$ & $75 \pm 1 \% \S$ & $73 \pm 2 \% \S$ \\
\hline Tibia wt & $76 \pm 1 \% \S$ & $66 \pm 2 \% \S$ & $37 \pm 7 \% \S$ \\
\hline Femur length & $78 \pm 1 \% \S$ & $73 \pm 1 \% \S$ & $76 \pm 3 \% \S$ \\
\hline Femur wt & $77 \pm 1 \% \S$ & $65 \pm 3 \% \S$ & $41 \pm 7 \% \S$ \\
\hline Pelvis wt & $91 \pm 5 \%$ & $85 \pm 5 \% \S$ & $50 \pm 9 \% \S$ \\
\hline Fetal loss & $0 / 6$ & $0 / 6$ & $10 / 17$ \\
\hline
\end{tabular}

* Heme $(\mathrm{H})$ and bilirubin $(\mathrm{B})$ doses expressed as injected vol in $\mathrm{mL}$, mean $\pm \mathrm{SEM}$.

$\uparrow$ Growth parameters as absolute measurements.

$\ddagger$ Growth parameters as percentages of the appropriate control within each assay.

$\S p<0.05$ vs control.

Table 5. Effect of bilirubin/Hb on growth of embryonic chick long bones in organ culture in vitro*十

\begin{tabular}{lcccc}
\hline & T0 & T2 (\% T0) & T5 (\% T0) & Dry wt (\% control) \\
\hline Pelvic rudiment (mg) & & & & \\
Control & $4.95 \pm 0.16(66)$ & $166 \pm 3(66)$ & $287 \pm 10(66)$ & \\
Bili 0.05 mM & $5.21 \pm 0.16(49)$ & $146 \pm 3(49) \ddagger$ & $218 \pm 6(49)$ & \\
Hb 0.025 mM & $4.91 \pm 0.14(51)$ & $138 \pm 2(51) \ddagger$ & $201 \pm 4(51)$ & \\
Tibia (mm) & & & & \\
Control & $9.2 \pm 0.1(42)$ & $114 \pm 1(57)$ & $123 \pm 2(36)$ & $0.78 \pm 0.02 \mathrm{mg}(87)$ \\
Bili 0.05 mM & $8.7 \pm 0.2(30)$ & $107 \pm 2(38) \ddagger$ & $118 \pm 3(37)$ & $90 \pm 2(74) \ddagger$ \\
Hb 0.025 mM & $8.3 \pm 0.2(34)$ & $105 \pm 2(39) \ddagger$ & $119 \pm 3(14)$ & $84 \pm 2(67) \ddagger$ \\
Femur (mm) & & & & \\
Control & $6.6 \pm 0.1(47)$ & $119 \pm 1(47)$ & $125 \pm 2(29)$ & $0.63 \pm 0.02 \mathrm{mg}(81)$ \\
Bili 0.05 mM & $7.1 \pm 0.1(29)$ & $108 \pm 2(35) \ddagger$ & $113 \pm 2(23) \ddagger$ & $92 \pm 2(59) \ddagger$ \\
Hb 0.025 mM & $6.4 \pm 0.1(39)$ & $105 \pm 2(38) \ddagger$ & $118 \pm 3(9)$ & $100 \pm 2(64)$ \\
\hline
\end{tabular}

* T0 measurements expressed as absolute units; $\mathrm{T} 2$ and $\mathrm{T} 5$ expressed as percentages relative to measurements for each segment. Abbreviations: bili, bilirubin, T0, d 0 measurements; T2, after $2 \mathrm{~d}$ incubation; T5, after $5 \mathrm{~d}$ incubation.

$\dagger$ Numbers in parentheses are the number of bone segments.

$\ddagger p<0.05$ vs controls.

The definition of the exact role of tetrapyrroles as endogenous metabolic inhibitors and the investigation of their range and mechanisms of tissue action requires the creation of suitable experimental models. In clinical diseases, it is difficult to separate the effect of elevated heme compounds from the consequences of coexisting nutritional/metabolic systemic abnormalities. Similarly, in observations of mammalian pregnancies, derangements of the maternal milieu directly affect the fetal metabolism through transplacental transfer.

We found a reproducible, although modest, inhibition of embryonic growth after the introduction of small doses of either bilirubin or heme in ovo; the tetrapyrroles interfered with both long and flat bone growth both in ovo and in vitro. The findings are consistent with our earlier studies (4-9), except for the toxic and irreversible component of tissue action, which was not readily apparent in vitro. In addition, these compounds appear to influence the development of a variety of fetal tissues, suggesting that they may possess a wider range of antianabolic bioactivity than appreciated earlier.

Acknowledgment. The authors thank Ms. Laura Claburn for her expert preparation of the manuscript.

\section{REFERENCES}

1. Kitay DZ (ed) 1987 Hematologic Problems in Pregnancy. Med Economics, Oradell, NJ, pp 116-177

2. Bergstein NAM 1973 Abnormalities of liver function during pregnancy. In: Liver and Pregnancy. Excerpta Medica, Amsterdam, pp 35-52

3. Lowensohn RI, Devoe LD 1984 Maternal disease In: Lin CC, Evans MI (eds) Intrauterine Growth Retardation: Pathophysiology and Clinical Management. McGraw-Hill, New York, pp 145-150

4. Vassilopoulou-Sellin R, Oyedeji CO 1988 Tetrapyrroles as inhibitors of normal cartilage metabolism: relative potency of different compounds. J Bone Miner Res 3:681-688

5. Vassilopoulou-Sellin R, Oyedeji CO, Foster PL, Thompson MM, Samaan NA 1989 Hemoglobin as a direct inhibitor of cartilage growth in vitro. Horm Metab Res 21:11-14

6. Vassilopoulou-Sellin R, Thompson MM, Oyedeji CO, Samaan NA 1989 Heme inhibits cartilage metabolism and growth in vitro. Metabolism 38:52-56

7. Vassilopoulou-Sellin R, Oyedeji CO, Samaan NA 1989 Bilirubin inhibits cartilage metabolism and growth in vitro. Metabolism 38:759-762

8. Vassilopoulou-Sellin R, Oyedeji CO 1989 Heme overload inhibits the growth of normal rats. Growth Dev Aging 53:123-127

9. Vassilopoulou-Sellin R, Rey-Bear N, Oyedeji CO 1990 Bilirubin as an inhibitor of cartilage metabolism: effect of avian chondrocyte proliferation in cell culture. J Bone Miner Res (in press)

10. Girbau M, Gomer JA, Lesniak MA, de Pablo F 1987 Insulin and insulin-like growth factor I both stimulate metabolism, growth and differentiation in the postneurula chick embryo. Endocrinology 121:1477-1482

11. Robel EJ, Christensen VL 1987 Increasing hatchability of turkey eggs with biotin egg injections. Poult Sci 66:1429-1430

12. Doi O, Hutson JM 1988 Pretreatment of chick embryos with estrogen in ovo 
prevents mullerian duct regression in organ culture. Endocrinology 122:2888-2891

13. Kappas A, Song CS, Levere RD, Sachson RA, Gromick S 1968 The induction of $\delta$-aminolevulinic acid synthetase in vivo in chick embryo liver by natural steroids. Proc Natl Acad Sci USA 61:509-513

14. Anderson KE 1978 Effects of antihypertensive drugs on hepatic heme biosynthesis and evaluation of ferrochelatase inhibitors to simplify testing of drugs for heme pathway induction. Biochim Biophys Acta 543:313-327

15. Anderson KE, Drummond GS, Freddara U, Sardana MK, Sassa S 1981 Porphyrogenic effects and induction of heme oxygenase in vivo by $\delta$-aminolevulinic acid. Biochim Biophys Acta 676:289-299

16. Williams WJ, Bentler E, Ersley AJ, Lichtman MA (eds) 1983 Hematology. McGraw-Hill, New York

17. Ostrow JD (ed) 1986 Liver: Normal Function and Disease. Vol 4, Bile Pigments and Jaundice: Molecular, Metabolic and Medical Aspects. Dekker, New York

18. Clayton RJ 1969 Byler disease: fatal familial intrahepatic cholestasis in an Amish kindred. Am J Dis Child 117:112-117

19. Jones EA, Rabin L, Buckley H, Webster GK, Owens D 1976 Progressive intrahepatic cholestasis of infancy and childhood; a clinicopathologic study of a patient surviving to the age of 18 years. Gastroenterology 71:675-682

20. Riely CA, Cotlier E, Jensen PS, Klatskin G 1979 Arteriohepatic dysplasia: a benign syndrome of intrahepatic cholestasis with multiple organ involvement. Ann Intern Med 91:520-527

21. Drexler HG, Gaedicke G, Minowada J 1986 Erythroleukemia cell lines HEL and $\mathrm{K} 562$ : changes in isoenzyme profiles and morphology during induction of differentiation. Hematol Oncol 4:163-168

22. Malik Z, Agam G, Djaldetti M, 1979 Effect of hemin and protoporphyrin IX on the protein-synthesizing activity of human granulocytes, lymphocytes and platelets. Acta Haematol (Basel) 61:138-140

23. Lin GS, Al-Dakan AA, Gibson DP 1986 Inhibition of DNA and protein synthesis and all division by photoactivated haematoloporphyrin derivative in hamster ovary cells. Br J Cancer 53:265-267

24. Verma A, Nye JS, Snyder SH 1987 Porphyrins are endogenous ligands for the mitochondrial (peripheral-type) benzodiazepine receptor. Proc Natl Acad Sci USA 84:2256-2260

25. Snyder SH Verma A, Trifiletti RR 1987 The peripheral-type benzodiazepine receptor: a protein of mitochondrial outer membranes utilizing porphyrins as endogenous ligands. FASEB J 1:281-288

26. Mustafa MG, Cowger ML, King TE 1969 Effects of bilirubin on mitochondrial reactions. J Biol Chem 244:6403-6414

27. Cowger ML Igo RP Labbe RF 1965 The mechanism of bilirubin toxicity studied with purified respiratory enzyme and tissue culture systems. Biochemistry 4:2763-2770

28. Elias MM, Comin EJ, Grosman ME, Galeazzai SA, Rodriguez-Garay EA 1987 Possible mechanism of unconjugated bilirubin toxicity on renal tissue. Comp Biochem Physiol [A] 87:1003-1007

29. Nakamura H, Uetani Y, Komura M, Takada S, Sano K, Matsu T 1987 Inhibitory action of bilirubin on superoxide production by polymorphonuclear leukocytes. Biol Neonate 52:273-278

30. Kessel D, Dougherty TJ (eds) 1983 Porphyrin Photosensitization. Advances in Experimental Medicine \& Biology series, Vol 160. Plenum Press, New York

31. Andreoni A, Cubeddu R 1983 Porphyrins in Tumor Phototherapy. Plenum Press, New York

32. Vassilopoulou-Sellin R, Oyedeji CO 1990 Hematoporphyrin can inhibit the metabolism and growth of embryonic chicken cartilage in vitro. Metabolism (in press)

33. Berns MW, Wile A, Dahlman A, Johnson F, Burns R, Sperling D, Guiltinan M, Siemens A, Walter R, Hammer-Wilson M 1983 Cellular uptake, excretion and localization of hematoporphyrin derivative (HPD). Adv Exp Med Biol 160:139-150

34. Canti G, Ricci L, Franco P, Nicolin A, Andreoni A, Cubeddu R 1983 Hematoporphyrin derivative phototherapy in experimental oncology. In: Andreoni A, Cubeddu R (eds) Porphyrins in Tumor Phototherapy. Plenum Press, New York, pp 203-212 